\title{
Caciques, jesuitas y chamanes en la frontera sur de Buenos Aires (1740-1753)
}

\author{
Raúl Hernández Asensio
}

Instituto de Estudios Peruanos. Lima

\begin{abstract}
El artículo analiza la evolución de tres misiones fundadas por la compañía de Jesús al sur del río Salado, en la gobernación de Buenos Aires, entre los años 1741 y 1753. Estos establecimientos se encontraban situados muy al sur de la frontera que separaba las sociedad indígenas y la sociedad hispano-criolla. Su fundación tiene lugar en un periodo en el cual ambas sociedad estaban experimentando importantes cambios, sobre todo debidos a la consolidación de nuevas rutas comerciales interculturales. En concreto se estudia la dinámica interna de estas misiones, a partir de la relación entre los caciques indígenas reducidos, los padres jesuitas y los chamanes indígenas.
\end{abstract}

Palabras Claves: Frontera, Pampa, Relaciones interétnicas, Jesuitas, Misiones.

This article analyses the evolution of three missions founded by the Company of Jesus south of the río Salado, in the gobernación of Buenos Aires, between the years 1741 and 1753. These missions were located well to the south of the frontier which separated Indian from hispano-creole society. Their foundation occurred during a period when both societies were undergoing significant changes, above all due to the consolidation of new intercultural trade routes. Specifically, the article studies the internal dynamics of these missions, on the basis of relations between the settled Indian caciques, the Jesuit priests, and indigenous shamans.

KEYwORDS: Frontier, Pamp, Interethnic relations, Jesuits, Missions.

A comienzos del siglo XVIII los asentamientos hispanos en el río de la Plata apenas habían avanzado más allá de los límites de colonización establecidos doscientos años atrás. Durante ese siglo, la cesura del río Salado establece la frontera entre dos mundos. De una parte, la sociedad criolla de Buenos Aires y su campaña aledaña; de otra, las semidesconocidas sociedades indígenas de las Pampas. En el curso de los siguientes cien años, sin embargo, el panorama iba a cambiar de manera notable. El siglo XVIII es un periodo de transformaciones radicales en los espacios abiertos de las Pampas y la Patagonia. Desplazamientos de población entre unas zonas y otras, y el establecimiento de una compleja red de interrelaciones políticas y económicas más allá de las fronteras étnicas, son elementos a tener en cuenta a la hora de trazar la historia de aquellos años. Ésta es una historia caracterizada por el surgimiento de nuevas identidades, tanto entre quienes hasta entonces habían venido formando parte de un asentamiento 
marginal del imperio hispano de América, como entre las poblaciones indígenas del área. Una historia de interrelación dinámica en la cual, como vamos a tratar de demostrar, la agencia histórica corresponde a unos y otros, tanto a criollos como a indígenas.

Las siguientes páginas tratan de ser un acercamiento a todo ello. Un acercamiento a través de un estudio de caso, un ejemplo concreto y temprano de aquello que iba a ser norma a lo largo de los siglos siguientes: los intentos criollos de expansión hacia las tierras al sur del río Salado y los consiguiente esfuerzos por asimilar a las poblaciones nativas pampeanas dentro de los esquemas propios de poblamiento. Con este objeto estudiaremos el desenvolvimiento del proyecto jesuita de establecer misiones en las serranías del Tandil y el Volcán, entre los años 1740 y 1753, en el marco de las transformaciones estructurales que, como hemos dicho, por entonces afectaban a toda la región. Gracias a ello podremos observar con cierto nivel de detalle las respuestas ensayadas por las poblaciones indígenas y sus diversas estrategias de relación entre estas poblaciones y las criollas.

\section{Hacia un nuevo modelo: el comercio y su influencia en la transformación de los patrones indígenas de poblamiento}

La historiografía tradicional, anterior a la década de 1980, había caracterizado a las sociedades indígenas pampeanas con unas pocas líneas gruesas, haciendo especial incidencia en dos puntos: su carácter depredador (cazador-recolector) y su pretendido nomadismo. Frente a esta pretendida homogeneidad, la producción de las últimas dos décadas ha contribuido significativamente a matizar estas imágenes, sacando a la luz un mundo mucho más variado y prolijo en matices enriquecedores. Este redescubrimiento se ha llevado a cabo desde distintas perspectivas. En un principio los estudios históricos del profesor Raúl Mandrini ${ }^{1}$ supusieron una ruptura importante, posteriormente consolidada por los avances registrados en dos líneas de investigación, hasta hace poco escasamente tratadas: la arqueología y la etnohistoria. A través de estos nuevos trabajos, se ha venido avanzando en una nueva caracterización de las sociedades indígenas, sobre una triple base: a) reformulación y redefinición de sus bases mate-

1 Sobre este mismo tema, una versión preliminar de nuestra investigación se presentó en Procesos: revista ecuatoriana de historia, núm. 17, Quito, 2001 
riales, poniendo el acento en su complejidad y olvidando aquella antigua calificación de depredadoras. En este sentido, se ha avanzado en la caracterización de procesos regionales, especialmente en el estudio de los vastos circuitos comerciales interculturales, así como en los consiguientes procesos de especialización regional, a que dieron origen. ${ }^{2} b$ ) Replanteamiento de la idea de nomadismo, que no debe ser confundido con la movilidad comercial. En concreto, para el caso del sur de Buenos Aires, a partir de los trabajos de Raúl Mandrini sabemos que a lo sumo puede hablarse de seminomadismo estacional. ${ }^{3} c$ ) Descubrimiento de unas estructuras sociales y políticas complejas, con procesos de diferenciación social, de acumulación de riqueza, de formación de grandes unidades políticas y de concentración de autoridad. ${ }^{4}$

Históricamente el comercio no había sido una actividad ajena a las sociedades prehispánicas. Por el contrario, el intercambio de productos opera en las sociedades tribales como un poderoso mecanismo de articulación. Esto en dos sentidos. Primero, desde el punto de vista económico, como redistribuidor del excedente, el comercio facilitaría la articulación entre grupos distantes con accesibilidad a recursos diversos. Además, desde el punto de vista social, bien como trasunto de la guerra bien como táctica impuesta por la necesidad de establecer alianzas, el intercambio recíproco de bienes constituye una pieza angular de la "política exterior"

2 Citamos únicamente algunos ejemplos significativos: León Solís, Leonardo: "Comercio, trabajo y contacto fronterizo en Chile, Cuyo y Buenos Aires, 1750-1800", Runa. Archivo para las Ciencias del Hombre, núm. 19, Buenos Aires, 1991; y más en general León Solís, Leonardo: Maloqueros y conchavadores en Araucania, Patagonia y las Pampas, Temuco, 1991; Nacuzzi, Lidia R. y Pérez de Micou, Cecilia: "Rutas indígenas y obtención de recursos económicos en Patagonia", Memoria Americana, núm. 3, Buenos Aires, 1994; y Ortelli, Sara: El proceso de "araucanización" de las pampas: balance y perspectivas, tesis de Licenciatura, Universidad Nacional del Centro de la Provincia de Buenos Aires, Tandil, 1994. Especialmente importante en este sentido, resultó el artículo de Palermo, Miguel A.: "Reflexiones sobre el llamado complejo ecuestre en la Argentina", Runa. Archivo para las Ciencias del Hombre, núm. 16, Buenos Aires, 1986; a partir del cual comenzó a olvidarse el empleo de aquel término de profundo recuerdo evolucionista.

3 Mandrini, Raúl: "Desarrollo de una sociedad indígena pastoril en el área interserrana bonaerense", Anuario del IEHS, núm. 2, Tandil, 1986; Mandrini, Raúl: "La agricultura indígena en la región pampeana y sus adyacencias", Anuario del IEHS, núm. 1, Tandil, 1986; Mandrini, Raúl: "Notas sobre el desarrollo de una economía pastoril entre los indígenas del suroeste bonaerense (finales del siglo XVIII-comienzos del XIX)", Etnía, núm. 34-35, Olavarría, 1989-1990; y Mandrini, Raúl: "Procesos de especialización regional en la economía indígena pampeana (siglos XVIII-XIX): el caso del suroeste bonaerense", Boletín Americanista, núm. 41, Barcelona, 1991.

4 Mandrini, Raúl: "Guerreros, pastores y comerciantes en la conformación de nuevos hábitos económicos indígenas en el siglo XVIII”, en XIII Jornadas de Historia Económica, Mendoza, 1992; Nacuzzi, Lidia R.: Los Tehuelches del norte de la Patagonia, tesis doctoral inédita, Universidad de Buenos Aires, 1996, capítulo 5 "El cacicazgo". 
tribal. ${ }^{5}$ En este sentido, el comercio estratégico fue abundantemente empleado por los españoles. El poder colonial redimensionó las funciones del comercio, hasta hacer del intercambio selectivo uno de los motores de la política fronteriza imperial, al tiempo que un elemento enculturador básico, con respecto a la articulación de las sociedades no directamente sometidas a la administración colonial.

Durante el siglo XVIII ambas expresiones de intercambio, la nativa y la imperial, estuvieron presentes en el comercio fronterizo. A través de los trabajos de Leonardo León Solís y Margarita Gascón, sabemos cómo este comercio fue incrementando su radio de acción, consolidando a lo largo de esta centuria vastos circuitos de intercambio que involucraban tanto a los indígenas pampeanos, patagónicos y chilenos, como a las colonias hispano-criollas de ambas gobernaciones. ${ }^{6}$ Según señala Margarita Gascón, a lo largo de doscientos años de colonización tuvo lugar un proceso de paulatina articulación horizontal de ambas fronteras, la chilena y la del Río de la Plata, con sentido oeste-este, comenzando al sur del Valle Central chileno y culminando con la integración del mundo fronterizo pampeano dentro de estos circuitos. Para mediados del siglo XVIII, coincidiendo con el fin de las cacerías de ganado cimarrón en la Banda Oriental, asistimos a la fijación definitiva de una serie de rutas comerciales ampliamente frecuentadas de uno y otro lado de la frontera. Cristaliza en ese momento un espacio comercial singular. La intensificación del comercio fronterizo, perceptible sobre todo en el último tercio del siglo XVIII, habría producido una transformación del sistema de intercambios entre ambas sociedades que había prevalecido anteriormente. El flujo casual anterior, más o menos intenso según las ocasiones, se fue regularizando hasta transformarse en una actividad periódica, provocando un desajuste estructural del sistema económico tribal, el cual se iba a transformar para adecuarse a las demandas y exi-

5 Mientras para Claude Levi-Strauss la guerra sería resultado del fracaso de las relaciones comerciales dentro de un contexto de necesidad - al tiempo económica y sobre todo social— de establecer relaciones con otros grupos humanos, para Pierre Clastres, al contrario, el intercambio de bienes sería sólo una necesidad táctica, con objeto de obtener alianzas provisionales, dada la imposibilidad de mantener una guerra activa contra todos los pueblos vecinos a un tiempo. Al respecto, la polémica entre ambos se recoge en: Clastres, Pierre: "Arqueología de la violencia: la guerra en la sociedad primitiva", en Investigaciones en antropología política, Barcelona, 1996, págs. 186-219, por cierto uno de los pocos artículos en que el autor se muestra respetuoso y atento a la opiniones de sus contradictores.

6 Gascón, Margarita: "La articulación de Buenos Aires a la frontera sur del imperio español, 1640-1740”, Anuario del IEHS, num. 13, Tandil, 1998; y León Solís, Leonardo: "Maloqueros y tráfico ganadero" en Maloqueros y conchavadores en Araucanía, Patagonia y las Pampas: 1700-1800, Temuco, 1991. 
gencias del comercio intercultural. Por supuesto, estamos hablando de procesos de larga duración, comenzados quizás en el siglo XVI, al albur de la creciente necesidad de caballos experimentada por los araucanos chilenos durante las guerras coloniales. Un proceso que si, en un principio, había afectado únicamente a las tribus más occidentales cercanas a la cordillera, a principios del XVIII comenzaba a modificar radicalmente todo el panorama del área pampeana-patagónica. Para el periodo de nuestro estudio, aunque incipientes en muchos aspectos, gran parte de los cambios sociales y económicos, provocados por este nuevo esquema de relaciones, comenzaban a ser perceptibles entre las tribus del sur y del este de Buenos Aires. De esta época son los primeros testimonios de lo que Raúl Mandrini ha denominado sociedad indígena pastoril del área interserrana bonaerense. Estos grupos, situados en las abras de las serranías de la Ventana y la Tandilia, habrían constituido un caso particular de especialización productiva, dentro de ese contexto de creciente complejidad de las sociedades indígenas de que antes hablábamos. Mandrini señala cómo hacia el final de la época colonial: "Tal vez sean éstos los únicos grupos a los que quepa realmente tal denominación [criadores de ganado nómadas] según el modelo de pastoreo nómada del viejo mundo"?

Aparentemente, estaríamos, por lo tanto, ante una de las consecuencias de ese proceso de reestructuración del marco de relaciones regionales: la aparición de facies económicas especializadas en la producción de un tipo determinado de producto con destino a un mercado en expansión. Una sociedad ganadera, que concentraría de manera creciente sus esfuerzos en el cuidado y la conducción del ganado, primero caballar y más tarde sobre todo vacuno, entre las pampas de Buenos Aires y la cordillera andina. $\mathrm{La}$ documentación consultada, sin embargo, sugiere alguna matización. Los textos señalados por Raúl Mandrini, si bien son elocuentes, en su mayoría hacen referencia a un periodo posterior. Para la época central del siglo XVIII se trata de un proceso incipiente. En este sentido, las referencias a la caza como actividad básica de pampas y serranos de los años ' 40 y ' 50 del siglo XVIII son reiteradas en la mayor parte de los documentos. La caza de ganado caballar, bien fuera alzado o cimarrón, es una actividad cotidiana que estructura la vida del indígena, al punto que ni siquiera su reducción al régimen misional consigue imponer una norma de conducta diferente. Incluso, cuando encontramos referencias a la hacienda de ganados que los

7 Mandrini, Raúl José: “Desarrollo de una sociedad..., págs. 70-71. 
propios padres poseían en las cercanías de sus emplazamientos, especialmente junto a la costa de la actual Mar del Plata, es a trabajadores españoles e indios guaraníes que encontramos en ellas. Por supuesto, esto no desmiente totalmente la posibilidad de una incipiente ganadería indígena ajena al control misionero, ya que existen otras explicaciones posibles para esta ausencia de trabajadores locales, como vamos a ver más adelante, pero su importancia para la época estudiada debe ser matizada. Otro dato viene, además, a incidir en este sentido. En el segundo tercio del siglo XVIII, el comercio de ponchos y productos de cuero reviste una importancia fundamental. Podemos afirmar que era esta actividad la que mayormente despertaba el interés de caciques y hombres poderosos, pampas y serranos. Este comercio, que como hemos visto venía ya de antiguo, comenzaba a ser reglado a principios de la época de nuestro estudio, fecha para la que tenemos los primeros datos seguros de ferias fronterizas, en concreto los recogidos en las paces firmadas en 1742 entre el cacique Bravo y el Maestre de Campo Juan de San Martín. ${ }^{8}$ Las fuentes, sin embargo, insisten en que para estos años no eran los propios indios pampas y serranos quienes elaboraban los ponchos, no al menos mayoritariamente, sino que éstos procedían del comercio realizado con otras tribus occidentales, probablemente araucanizadas. ${ }^{9}$ Diversos autores señalan que, aunque de las fuentes jesuitas no es posible diferenciar entre araucanos y pampas a partir de la tenencia o no de ovejas, las técnicas textiles eran de origen chileno, estando su difusión ligada al proceso de araucanización. ${ }^{10}$ En resumen, con respecto al modo de

8 Capitulaciones de las paces hechas entre los indios Pampas de la reducción de Nuestra Señora de la Concepción y serranos, aucas y peguenches [1742?]. Real Academia de la Historia Colección Mata Linares (Madrid), vol. 66. ${ }^{\circ}$, págs. 420-421.

9 Explícitamente, el padre Cardiel: " $6 .^{\circ}$ que estos pocos aucaes y serranos en esa tierra venían a buscar yeguas y caballos, cada año para comer y caminar a Buenos Aires a comprar aguardiente para sus borracheras, y cascabeles y otros avalorios para sus fiestas, en trueque de ponchos que son la vestidura que sirve aquí de capa a la gente labradora [...]; 7. ${ }^{\circ}$ que los serranos no hacían ponchos, sino que se los compran a los aucaes a trueque de caballos, los cuales los aucaes los hacen en sus tierras donde tienen ovejas con más larga lana que la de otras partes [...]". Cardiel, José: Diario del viaje y misión al río del Sauce. Citado en Furlong, Guillermo: Entre los pampas de Buenos Aires: según noticias de los misioneros jesuitas Matías Strobel, José Cardiel, Tomás Falkner, Jerónimo Rejón, Joaquín Caamaño, Manuel Querini, Manuel García, Pedro Lozano y José Sánchez Labrador, Buenos Aires, 1938, pág. 140.

10 Un buen balance respecto a la araucanización en: Ortelli, Sara: El proceso de "araucanización" de las pampas: balance y perspectivas. Tesis de Licenciatura, Universidad Nacional del Centro de la Provincia de Buenos Aires, Tandil, 1994; y más sintéticamente Mandrini, Raúl y Ortelli, Sara: "Repensando los viejos problemas: observaciones sobre la araucanización de las pampas", Runa. Archivo para las Ciencias del Hombre, núm. 22, Buenos Aires, 1995; y Ortelli, Sara: "La araucanización de las pampas: realidad histórica o construcción de los etnólogos?", Anuario del IEHS, núm. 11, Tandil, 1996. 
vida de las poblaciones indígenas que habitaban el área misional de las serranías de Tandil y la Ventana, así como las zonas interserranas importa considerar tres puntos:

- Nos encontramos ante sociedades convulsionadas por un proceso de cambio social y económico cuyos efectos comenzaban ya a ser perceptibles para esta época.

- Desde el punto de vista económico, la tendencia es hacia un sistema de producción especializado, basado en la ganadería caballar y ovina, así como el comercio de ponchos y ganado con los poblados fronterizos.

- Sin embargo, para mediados del siglo XVIII, ambos fenómenos deben ser contextualizados en un marco donde aun predominaba la caza de ganado alzado o cimarrón como principal medio de obtención de alimentación y productos para el comercio.

\section{Padres, chamanes y caciques: el juego del poder en las misiones}

La historia es larga de contar. Los avatares de la confrontación fronteriza entre las sociedades criolla e indígena en la pampa atraviesan un periodo de crisis, durante las décadas tercera y cuarta del siglo XVIII. Malones, incursiones a veces de profundidad notable en las campañas cercanas a Buenos Aires, seguidas de la incapacidad de las autoridades coloniales para responder al nuevo desafío, determinaron, hacia 1745, un cambio en la estrategia de contención seguida hasta ese entonces. Para aquel año se autorizó a la Compañía de Jesús el establecimiento de una primera misión, Nuestra Señora de la Concepción, fundada cerca del río Salado. A ésta seguirían en corto plazo otras dos, las reducciones de Nuestra Señora del Pilar de los indios puelches —o serranos-, cerca de la actual ciudad de Mar del Plata, y la de Nuestra Señora de los Desamparados de Toelches, a unas pocas leguas de la anterior. Más allá de la anécdota histórica, el estudio de estos efímeros emplazamientos puede proporcionarnos datos valiosos para comprender mejor la naturaleza de los complejos procesos de reafirmación de identidades y etnogénesis que caracterizan al siglo XVIII pampeano. A ello dedicaremos el resto de este artículo.

La historia de estas misiones constituye un tema que aun no ha sido suficientemente tratado dentro de la historiografía relativa a la frontera sur 
de Buenos aires. Aunque las desventuras de los padres jesuitas son suficientemente conocidas y es posible encontrar referencias a ellas en muchos textos, en pocas ocasiones se ha profundizado al respecto. En este sentido el principal estudio corresponde al padre Furlong, quien en su estudio sobre las sociedades indígenas de la región, publicado durante la década de 1930, hace abundante uso de parte de la documentación existente al respecto. El texto de Furlong tiene el mérito de la descripción minuciosa y el gusto por el detalle concreto. Para el historiador actual, sin embrago, su utilización plantea algunos problemas. La intencionalidad apologética, implícita en todas sus páginas, lleva al autor a dar por buenos, sin mayor crítica, los juicios emitidos por los propios protagonistas jesuitas de la historia, respecto a las misiones y la actitud de indígenas e hispano-criollos. Posteriormente a esta obra, poco se ha escrito. En los últimos años una serie de ponencias y comunicaciones han tratado de presentar nuevas visiones respecto a la problemática reflejada. Sin embargo, por el momento se trata de avances de investigación, referidos a proyectos aun sin cristalizar $^{11}$. De alguna manera, el trabajo que nosotros presentamos también se incluye dentro de esta última categoría. El presente artículo es parte de una investigación que aun tenemos en curso. En este sentido, para nuestros objetivos a diferencia del padre Furlong nos hemos basado sobre todo en documentos conservados en el Archivo General de Indias. Como se verá más adelante, estos documentos han resultado especialmente interesantes, sobre todo en lo referido a los modalidades de relación entre las sociedades indígena e hispano-criolla en el contexto de la práctica misional.

Durante su labor al sur del Salado, los padres jesuitas trataron de implementar el modelo de reducción que tan buen resultado había tenido entre los guaraníes del Paraguay. Autonomía y autosuficiencia: el ideal de la separación entre las repúblicas de indios y de españoles. Como han señalado Bareiro Saguier y Helene Clastres, fue esta visión utópica de la nueva América, de la nueva cristiandad, la que determinó el actuar de los padres en todos los campos de su labor misional, aquélla que tiznó con un color particular a su obra americana, diferenciándola de la llevada a cabo por las

11 Tejerína, Marcela Viviana: "El gobierno español y las reducciones jesuitas la sur de la provincia e Buenos Aires: el caso del fracaso de Nuestra Señora de la Concepción de los Pampas (17511753)", Revista de Historia de América, núm. 121, Buenos Aires, 1996 e Iglesias, Miriam: "Las misiones jesuitas al sur del río Salado y la frontera bonaerense en el siglo XVIII" en Negro, Sandra y Marzal, Manuel (coordinadores): Un reino en la frontera. Las misiones jesuitas en la América española, Lima, 1999 
demás órdenes religiosas. ${ }^{12}$ También para el caso de Buenos Aires, la aspiración a la separación entre blancos y neófitos estuvo presente. Una de las condiciones impuestas por el entonces padre provincial, Antonio Macchoni, antes de aceptar el encargo que le hacía el gobernador Salcedo apuntaba en este sentido. También algunas de las disposiciones tomadas, más adelante, por su sustituto, Manuel Querini, durante su primera visita a la reducción de la Concepción en el verano de 1748:

propuso cinco medidas a su parecer convenientes a la consecución de dicha empresa [...] $2^{\circ}$, que la reducción se haga 40 ó 50 leguas, por lo menos de Buenos Aires, por las malas consecuencias de su vecindad con los españoles. ${ }^{13}$

$8^{\circ}$ Evítese cuando se pueda el que los indios del pueblo vayan a la ciudad y para que no les valga la excusa de vender sus cosas o comprar lo que necesitan, se les dirá que lo que quisieran enviar a la ciudad se remitirá en la carreta del pueblo al Padre Procurador para que lo venda a cuenta de ellos y les remita según su producto, lo que ellos pidieren. ${ }^{14}$

Claro que una cosa eran los deseos y otra bien distinta su realización; una las ideas y otra su plasmación temporal. Conviene reiterar, como se ha hecho tantas veces, que nos encontramos ante un espacio geográfico, la pampa de Buenos Aires, de interés secundario, no sólo para la corona, sino también dentro de las propias estrategias de la Compañía. Más allá de los discursos y de las indudables esperanzas depositadas en la región, ésta nunca consiguió suscitar el suficiente interés como para justificar el desplazamiento de los misioneros y los recursos necesarios para su consolidación. Tanto la Concepción como, más adelante, las nuevas fundaciones

12 Barreiro Seguier, Rubén y Clastres, Helene: "Aculturación y mestizaje en las misiones jesuíticas del Paraguay", Aportes, núm. 14, París, 1968. Sobre el accionar jesuita la literatura existente es abrumadora, por lo que sólo citamos, a continuación, aquellas obras que más directamente influyeron en la realización de las siguientes páginas: Santamaría, Daniel: Del tabaco al incienso: Reducción y conversión en las misiones jesuitas de las selvas sudamericanas (siglos XVII y XVIII), San Salvador de Jujuy, 1994; Pinto Rodríguez, Jorge: "Frontera, misiones y misioneros en Chile: La Araucanía, 1600-1900”, en Misioneros en la Araucanía (1600-1900): un capítulo en la historia fronteriza de Chile, Temuco, 1988; y Foerster, Rolf: Jesuitas y mapuches: 1593-1767, Santiago de Chile, 1996. Por último, aunque orientado al estudio de la obra franciscana, puede consultarse el reciente y documentado artículo de Brandes, Stanley: "Las misiones de la Alta California, como instrumentos de conquista" en Gutiérrez Estévez, Manuel (ed.) et. al.: De palabra y de obra en el Nuevo Mundo: 2. Encuentros Interétnicos: interpretaciones contemporáneas, Madrid, 1992.

13 Dictamen del Fiscal del Consejo de Indias sobre la nueva reducción y población de los infieles de nación pampa. Sevilla. Agosto 11, de 1741. Archivo General de Indias (AGI), Charcas, 384.

14 Memorial del padre visitador Manuel Querini, superior de la Compañía de Jesús. Buenos Aires. Diciembre 29, de 1748. Archivo General de la Nación (AGN, Buenos Aires), Compañía de Jesús, 1748, citado en Furlong, Guillermo: Entre los pampas..., pág. 112. 
del Pilar y los Desamparados dependieron en todo momento de Buenos Aires, así en lo referido a pertrechos como a protección. Enclavadas las misiones más allá de la frontera, en territorio de un enemigo por lo general hostil, los padres no pudieron implementar sus planes de separación, debiendo recurrir, desde muy temprana fecha, a la protección del gobernador mediante la instalación de un cuerpo de guardia permanente en el interior del poblado, compuesto por un número fluctuante de soldados, casi siempre entre ocho y quince. La propia estructura económica de la región, con un complejo sistema de circuitos comerciales — como hemos visto en la tesitura de un periodo de consolidación y expansión- gravitó en un sentido contrario a los planes iniciales. Todo ello será examinado en las páginas que siguen, comenzando a continuación con la organización política de los poblados.

Puede que, como se ha señalado alguna vez, desde el punto de vista jesuita, evangelizar no equivaliera necesariamente a castellanizar. En todo caso, parece innegable que al menos la occidentalización era considerada una premisa básica a la hora de pensar el proceso de reducción de las tribus aborígenes de América. ${ }^{15}$ La asimilación de la cultura autóctona a los patrones de comportamiento y organización social propios del hombre blanco del siglo XVIII, aparece como uno de los objetivos básicos de las misiones. En este sentido apuntan muchos de los rasgos propios de los emplazamientos que estamos estudiando y, en primer lugar, la transformación del hábitat cotidiano. La re-socialización del espacio mediante el cambio en las estructuras habitacionales propias de los pueblos pampeanos es un parte importante del proyecto de los padres jesuitas. Las primeras descripciones de la misión en la Concepción hacen aun referencia a la permanencia de los citados toldos:

Iban con los padres algunos oficiales trabajadores para levantar unas chozas, en que vivir, cuya fábrica les costó poco, porque no se emplearon otros materiales que unos viles palos y alguna paja. Los indios por entonces se quedaron en sus toldos. ${ }^{16}$

Sin embargo, desde aquellos primeros días, trataron los padres de invertir esta situación, de transformar aquellos vestigios de la vida anterior

15 Pinto, José: "Frontera, misiones y..., pág. 35, señala: "Los misioneros no quieren un mero cambio cultural; se afanan por conseguir un reemplazo cultural. Vacían para llenar de nuevos contenidos a pueblos enteros que pierden así su derecho a pensar y vivir el mundo a su manera".

16 Sánchez Labrador, José: El Paraguay Catholico, citado en Furlong, Guillermo: Entre los pampas..., pág. 94 . 
de los nuevos neófitos. Esta mutación, sin embargo, no se hizo sin oposición ni resistencia:

la iglesia y la casa acabadas y aquella con los mejores adornos, que lo que en tan poco tiempo podía esperarse. Pero en los indios revivían sus ánimos inveterados [...] tenían los pampas mucho apego a sus toldos de cueros de caballo; para que los dejaran y asegurarlos más, los misioneros les hicieron fabricar casa unas de tapia, y otras de paja. ${ }^{17}$

Con el tiempo, las nuevas estructuras de habitación fueron haciéndose más comunes, a juzgar por los testimonios posteriores, referentes a los años siguientes a la primera fundación. Hacía 1746, el pueblo de la Concepción iba tomando el aire de una reducción jesuita, según el modelo clásico del Paraguay. Una plaza central y en torno a ella la iglesia, la casa del misionero, el cementerio y las casas de los indios. De creer al padre Furlong, parece que por entonces se habían construido tres casas continuadas, esto es, tres cuerpos de edificio que cerraban tres lados de la plaza, teniendo cada uno una extensión de ochenta a cien metros y divididos mediante tabiques en quince o más habitaciones grandes, las que a su vez estaban divididas en otras menores. ${ }^{18} \mathrm{El}$ uso de estas edificaciones debió ser desigual, dependiendo de las épocas y la voluntad de cada uno de los grupos posteriormente reducidos, pues en las fuentes abundan tanto los términos casa o choza, como el propio de toldo, empleados para referirse a la habitación de los indígenas reducidos. Para fechas bien tardías seguían existiendo en el interior de los poblados dos cementerios, uno para aquellos indios convertidos, otro para quienes seguían fieles a la fe de sus antepasados. E incluso así, las confusiones al respecto indican que no se había avanzado demasiado en cuanto a la introducción de nuevas pautas ideológicas de representación del territorio cotidiano:

Antes de morir [el cacique Mayu Don Carlos] pidió con instancias a los misioneros enterrasen su cuerpo en el cementerio, y que no permitiesen fuese llevado al enterramiento de los infieles. ${ }^{19}$

[Declara el alférez Antonio Barragán] un hecho que sucedió en dicho pueblo fue el que habiendo muerto el hijo de Pedro Izarra indio pampa de dicho pueblo con todos los sacramentos lo enterraron en un paraje que llaman en Campo Santo destinado para

17 Ibídem, pág. 106.

18 Furlong, Guillermo: Entre los pampas..., pág. 109. Parece basarse en la Numeración anual del pueblo de la Concepción de los indios pampas, correspondiente a los años, 1743-1744, 1745 y 1746. Biblioteca Nacional (Buenos Aires), Sección Manuscritos.

19 Sánchez Labrador, José: El Paraguay Catholico, citado en Furlong, Guillermo: Entre los pampas..., pág. 167. 
ello el cual terreno está cercado y cómo a su padre le hiciese cargo el que declara por haber visto que habían muerto tres caballos del difunto alrededor del cerco inmediato a la sepultura de que cómo siendo cristiano hacía aquello que era a la moda de los infieles [semitachado en el documento] ya que el dicho Pedro Yzarra le señaló lo han hecho sus parientes. ${ }^{20}$

Como la mayoría de las misiones americanas, en las situadas al sur del Salado, las estructuras locales de poder se basaron en una lógica bicéfala, que mezclaba poder civil y religioso, siendo las relaciones entre ambas instancias siempre desiguales. Primero, estaban los padres, formalmente la instancia superior de decisión, como había quedado determinado de modo explícito en el momento de constitución del asentamiento de la Concepción, a través de las palabras del Maestre de Campo Juan de San Martín, el mismo 13 de mayo:

para la buena disposición de todo ayudó grandemente la presencia del maestre de campo quien, en presencia del padre Manuel Querini, después de indicar las cosas necesarias para la buena marcha del pueblo, constituyó el cabildo con los cinco caciques y habiendo dividido entre ellos los regalos que llevaba a este fin, exhortó a la obediencia a los padres en primer lugar, y a la unión y al respeto para con el cabildo recién fundado. ${ }^{21}$

Los padres, con el explícito respaldo de la fuerza militar española, a un lado. Del otro, el cabildo indígena, constituido a imitación de los existentes en las ciudades de españoles, a partir de regidores y alcaldes. Este cabildo indígena estaba pensado como lugar de reunión y discusión de los principales miembros de la comunidad, como espacio para su asimilación a las pautas occidentales de gobierno. Elegidos anualmente, se conservan las actas de constitución de algunos de estos cabildos, tanto para el caso de la Concepción, como para el del pueblo del Pilar. ${ }^{22}$ Aunque sus funciones se centraban principalmente en el mantenimiento del orden interno, quizás por su escasa representatividad, quizás por responder a un patrón de organización difícil de encajar con la estructuras políticas del mundo indígena, su papel a

20 Copia de la Información hecha sobre la reducción de los indios pampas, que están al cargo de los RR.PP. de la Compañía de Jesús. Buenos Aires, 1752. AGI (Sevilla), Charcas, 221. El ritual seguido puede verse cómo guarda notable similitud con aquel descrito por el padre Quiroga, encontrado por los jesuitas que bajaron hacia la costa patagona a bordo del San Antonio. En Relación diaria que hace al rey nuestro Señor, que Dios Guarde, el padre Joseph Quiroga... [viaje al sur]. Buenos Aires. Abril 4, de 1746. AGI (Sevilla), Buenos Aires, 302.

21 Lozano, Pedro: Litterae Annae. VII. De Missione et Reducione Pampearum fundata anno 1740, citado en Furlong, Guillermo: Entre los pampas..., pág. 94.

22 En la obra del padre Furlong se reproducen las del año 1751, para ambos casos. Furlong, Guillermo: Entre los pampas..., págs. 121 y 159, respectivamente. 
lo largo de los años que estudiamos fue opaco. ${ }^{23}$ Constantemente ignorados por sus propios congéneres, los cabildantes indígenas apenas jugaron papel alguno de importancia, atrapados como estaban entre dos contradicciones: entre el poder pretendidamente omnímodo de los padres para castigar y repartir alimentos y las redes de clientela indígenas, no supieron -0 no pudieron- encontrar un lugar propio dentro de las estructuras locales de poder. Para comprender este punto hay que de pensar en términos de comunidades pequeñas, de superposición a veces innecesaria de roles. Mediatizados por su necesidad de mantener el control sobre grupos heterogéneos de neófitos, los padres se encontraban ante el siguiente dilema: o bien apoyarse en las estructuras tradicionales de poder, eligiendo para los cargos de responsabilidad a personajes de reconocida influencia (con lo que la propia dignidad del cabildo quedaba opacada ante los componentes tradicionales del liderazgo), o bien colocar en su lugar a individuos más dóciles, ajenos a estas estructuras tradicionales (con el resultado evidente de la pérdida de representatividad de los cargos en cuestión). En realidad, el nudo del problema residía en la imposibilidad de los padres para sustituir los mecanismos tradicionales a través de los cuales se ejercía el poder - sobre todo el prestigio y las relaciones clientelares- por otros nuevos, más acordes al ideal de modelo hispánico. O más sencillo aun, en la imposibilidad de sustituir a los caciques en la cúspide de estas redes, pese a los evidentes intentos en este sentido.

Podemos tratar de profundizar un poco más en estas hipótesis. Frente al indígena, el padre representaba un papel ambiguo, difícil de encuadrar dentro de las categorías consuetudinarias, precisamente porque compartía características de varias de ellas. El juego interno del poder dentro de los grupos pampeanos derivaba de la tensión constante entre dos categorías de líderes: el líder militar o guerrero, cuya posición proviene, primero, del prestigio y, luego, de la consolidación de redes de clientela a través de la redistribución selectiva de bienes; y el chamán, el líder trascendente, que debía su de influencia a una pretendida relación peculiar con los espíritus. Entre ambos, compartiendo rasgos de uno y de otro, se ubicaba el padre. Por un lado, fuente de bienes materiales a través del reparto de dádivas a los caciques e incentivos a los neófitos ${ }^{24}$; de otro, investido del carisma, de la capacidad para

23 Por ejemplo, declaraba el cabo de escuadra, Ramón de Aparicio: "que aunque hay justicias de entre ellos, no la obedecen ni hacen uso", en Copia de la Información...

24 Abundantes ejemplos en la Copia de la Información... Además, el hecho es citado reiteradamente en la documentación de la época, tanto la emanada del cabildo como la producida por los propios padres. 
manipular a los espíritus, al tiempo que portador del mensaje de un dios pretendidamente único, que habría demostrado su poder mediante los terribles castigos ejecutados por sus fieles españoles. ${ }^{25}$ Atrapado en esa contradicción, el padre estaría contrayendo una doble deuda con la sociedad, a un tiempo material y mística. Utilizamos aquí el concepto de deuda, tal como lo ha definido Pierre Clastres ${ }^{26}$. En el caso de los padres, se trata de una deuda renovada cada día. Con cada entrega de bienes, el padre refuerza la obligación de seguir entregándolos, con cada demostración de poder espiritual establece la necesidad de superarse a sí mismo en la siguiente ocasión que sus servicios fuesen requeridos. De este modo, el padre, el misionero frente a sus neófitos indígenas, se habría convertido en deudor permanente, al tiempo que universal. De acuerdo a las categorías políticas indígenas podemos suponer que el padre jesuita debe haber sido una figura difícil de caracterizar. Por una parte, su poder pende en el frágil equilibrio del donativo, pues su actuación cotidiana despierta entre los indígenas expectativas similares a las de los liderazgos tradicionales. Sin embargo, se trata de un cacique redistribuidor peculiar, pues al mismo tiempo es capaz de proezas sobrenaturales y de descargar sobre el indígena toda la fuerza del español. En esta contradicción, las exigencias cotidianas aumentan, abarcan tanto lo material como lo extraordinario. Sin embargo, el padre, por su particular situación excéntrica a lo consuetudinario, no es capaz de introducirse en las estructuras de tradicionales de poder, continua siendo inaprensible. Como acertadamente expresaba un testigo en aquellos años:

[Declara el capitán Bentura Chavarría, sobre la conversión de los pampas] lo cual nunca lo podrán conseguir según lo rebelde que dichos indios son aunque dichos RR.PP. están siempre como sus feudatarios contribuyéndolos con el pan, yerba, tabaco, y demás procurándolos por este modo y por todos los demás que son dables y posibles atraer al fin que solicitan y por la poca sujeción y ninguna obediencia que

25 En este sentido, si bien el armamento indígena había ido adaptándose a las necesidades de la lucha contra los españoles, aun prevalecía el monopolio de las armas de fuego por parte de éstos. En 1749, señalaba al respecto el almirante inglés Georges Anson: "los indios de los alrededores de Buenos Aires se han convertido en excelentes jinetes y son extremadamente hábiles con el manejo de las armas cortantes, aunque ignoran el uso de las armas de fuego. Los españoles tienen cuidado de mantenerlas fuera de sus manos", citado en León Solís, Leonardo: Maloqueros y conchavadores..., pág. 119.

26 "Existe, sin embargo, un instrumento conceptual, generalmente desconocido por los etnólogos, que permite resolver muchas dificultades: la categoría de deuda [...] El líder está en situación de deuda con la comunidad precisamente porque es líder, y esta deuda no se puede pagar nunca, al menos durante el tiempo que desee seguir siendo líder ya que ella marca exclusivamente la relación que une a la jefatura con la sociedad. En el corazón de la relación de poder se establece la relación de deuda.". Clastres, Pierre: "La economía primitiva" en Investigaciones en antropología política, Barcelona, 1996, págs. 146-147. 
dichos indios guardan lo que le consta al declarante por haberlo dicho el padre Gerónimo Rexon cura de dicho pueblo que no moverían una paja para la fábrica de la iglesia sin que se les pague su mesnada o diariamente. ${ }^{27}$

En este sentido, carente de apoyos reales, el padre se hallaba rodeado de potenciales enemigos. De acuerdo con coyunturas concretas, su posición podía ser utilizada por caciques y chamanes en su lucha particular por consolidar su ascendiente personal. Sin embargo, una hipotética consolidación de los padres dentro de las estructuras indígenas, necesariamente habría terminado por socavar la posición de ambos personajes, caciques y chamanes, dentro de la tribu. Especialmente de éstos últimos, de los chamanes, precisamente porque la competencia aparecía en el plano cotidiano de manera más inmediata:

La perdición de muchos de los indios puelches nacía de la pertinacia en dejarse curar de sus hechiceros. Muchos enfermos eran de genios dóciles y que se inclinaban a recibir el Santo bautismo, oyendo a los misioneros. Pero los pervertían los hechiceros, de quienes esperaban la salud del cuerpo, fundados en los embustes que les oían [...] Previniendo este daño, en sabiendo los misioneros, que algún enfermo se dejaba curar del hechicero, no le acudían con cosas alguna, para que este castigo le hiciese abrir los ojos, y despedir al hechicero. En algunos surtía buen efecto esta traza y por el interés de la comida, no se dejaban curar del embustero, que los empobrecía, tomándoles sus alhajuelas, y dejándolos como estaban. Otros bellacos (y era lo común) se hacían curar del hechicero a media noche [...] Fui, dice un misionero, a catequizar a un mozo de edad de unos 20 años [...] oyó mis palabras con gusto, y repetía las vistas para instruirle, y recabar de él que no se dejase curar de un hechicero, que vivía en su mismo toldo y estorbaba su conversión [...] otra diligencia muy urgente me obligó a hacer la ausencia de un día. No perdió la coyuntura de mi ausencia una hechicera, que fue al toldo del enfermo a pervertirle, y se lo llevó otra vez a su toldo.28

\section{Claro que, en otras ocasiones, también ocurría justo lo contrario:}

Otro caso sucedió con el cacique Chuyantuya [...] Asaltado este miserable de un golpe de enfermedad penosa, se iba consumiendo, y llegado a lo último de sus días mal empleados. Curábanle los hechiceros, pero sin alivio porque el mal cobraba fuerzas. Fueron los padres Agustín Vilert y Matías Strobel a hablarle en el negocio de su alma. Oía bien lo que le decían de Dios, y de su salvación, mas en lo tocante a recibir el Bautismo, siempre le respondía, que después le bautizarían. El día mismo en que murió este infeliz, unas cuatro horas antes de su tránsito, le hablaron con eficacia los misioneros. Lo que recabaron del obstinado se redujo, a que les dijo, que reconocía

27 Copia de la Información...

28 Sánchez Labrador, José: El Paraguay Catholico, citado en Furlong, Guillermo: Entre los pampas..., pág. 163 . 
muy bien ser verdad lo que le decían, y así que al día siguiente le administrarían el bautismo. Instaban los misioneros, conociendo su riesgo, que mejor era recibirle luego; mas no pudieron convencerle; antes bien cuando se apartaron de su toldo, fue el hechicero, al cual para animarle y consolarle dijo: Cúrame que solamente por despedir de aquí a los padres, y que no me molestasen les he dicho, que mañana me bautizaran. ${ }^{29}$

Así, el chamán se convertía en el enemigo diario, en el obstáculo a vencer. Éste era un combate destinado a finalizar sin vencedores ni vencidos, un combate en el que cada victoria parcial requeriría de otra mayor que la consolidase, aun a riesgo de la propia vida de unos y otros. ${ }^{30}$ Pero, más allá de la letra, atreviéndonos a imaginar lo que en realidad recogen las fuentes, podemos aventurarnos a avanzar que no fue este enfrentamiento, entre padre y chamán, entre especialistas en lo sobrenatural, la causa de la imposible consolidación de las misiones del Salado. Se puede deducir de lo anterior que antes que oposición directa, la mayoría de los indígenas apreciaba entre padres y chamanes una especie de delicada complementariedad, competidores en un mismo campo, pero cuya existencia para nada perjudicaba al grupo en su totalidad. Competidores, pero no incompatibles. En este sentido, los ejemplos que siguen muestran bien a las claras cómo el papel de monaguillo o ayudante en la iglesia podía perfectamente convertirse en un aprendizaje para el posterior rol de chamán:

[Declara el alférez Antonio Barragán] y esto lo comprueba el que el indio que hacía de sacristán en dicho pueblo que no se acuerda su nombre sólo sí que es hijo de uno llamado Clemente que estuvo desterrado en Montevideo dejó el oficio de sacristán,

29 Ibídem, pág. 164.

30 Es conocida la costumbre pampa de ejecutar a aquellos hechiceros incapaces de cumplir su misión [Por ejemplo: Relación de las misiones que tienen actualmente la provincia del Paraguay de la Compañía de Jesús, escrita por el padre Manuel Querini. Córdoba del Tucumán. Agosto 1. , de 1750. AGI (Sevilla), Charcas, 215. ]. Lo cual, por otra parte, daba lugar a curiosas situaciones, como aquella también relatada por Sánchez Labrador: "No muchas leguas distante del lugar [...] estaba una toldería de indios puelches; en ella había un parvulito enfermo, hijo de un cacique. Curábale el hechicero, o le aceleraba la muerte con el ruido de su tambor o calabazo. Estaba ya la criatura en los últimos periodos de su corta vida, y desconfiando el hechicero de sus embustes, y temeroso del pago, que recibiría por ellos quitándole la vida, si moría el niño, tramó varias telas para salir de este aprieto. Entre otras ficciones propuso una, que le salió mal, sabía el hechicero que la madre de la criatura agonizante, estando en cinta había visitado la reducción de Nuestra Señora del Pilar, y adoró, aunque infiel, la imagen de un Santo Crucifijo [...] Dijo pues el hechicero, que su oráculo le había noticiado, que aquella enfermedad la causaba el Dios que tenían los Padres en su Iglesia [...] Concluyó, que el no podía curarla, por estar fuera de su ciencia tal enfermedad". Sánchez Labrador, José: El Paraguay Catholico, citado en Furlong, Guillermo: Entre los pampas..., pág. 190. Una vez más aparece clara la complementariedad. En este sentido, para épocas más recientes: Bacigalupo, Ana Marcela: "Variación del rol de machi dentro de la cultura mapuche: tipología y geografía adaptativa", Nütram, núm. 9/1, Santiago de Chile, 1993. 
y lo han visto vestido de china no sabe si lo sabrá el padre o no, y asimismo otro indio llamado Domingo Castellano que fue casado por la iglesia en dicho pueblo, y habiendo enviudado se fue a la sierra y allí anda vestido de china con zarcillos. ${ }^{31}$

Por lo tanto, no deben buscarse las causas de la no consolidación de las misiones en supuestas incompatibilidades religiosas o culturales. Debemos centrar nuestra atención en un tercer personaje, en la ambigua relación entre caciques y padres. Los mismos padres ya hemos visto cómo podían co-ayudar en el proceso de consolidación de las jerarquías autóctonas, utilizando a los caciques como intermediarios en el proceso de redistribución de bienes provenientes de la sociedad hispano-criolla. Sin embargo, su inserción estable entre los grupos indígenas ponía en peligro la continuidad de estas jerarquías. Para explicarlo con mayor claridad, vamos a estudiar a continuación la organización económica de nuestras misiones, su imbricación en el mundo del comercio y los intercambios fronterizos.

\section{Las Misiones y la lógica de la occidentalización de los indígenas pampeanos}

Tal como ha sido estudiado para el caso del Paraguay, el modelo clásico de economía jesuita se caracterizaba por la existencia de dos sectores complementarios: el comunal y el particular. ${ }^{32}$ Encargados de trabajar en ambos, los neófitos habrían dedicado algunos de los días de la semana a cuidar las tierras de los padres, aquellas cuyo fruto en teoría pertenecía a la totalidad de la comunidad, mientras el resto de los días, podían emplearlo en el cultivo de sus propias parcelas. Éste era un sistema que resultaba altamente productivo para la Compañía, tal como ha señalado Juan Carlos Garavaglia, sobre todo gracias a la comercialización de los excedentes de determinados bienes de amplia demanda en los mercados coloniales, tales como el tabaco o la yerba

31 Copia de la Información... Sobre la asociación entre chamanismo y travestismo, aparte del clásico de Metraux, Alfred: "El chamanismo araucano" en Religión y magias indígenas de América del Sur, (edición póstuma establecida por Simone Dreyfus), Madrid, 1973, podemos señalar la siguiente referencia: "Entre los puelches serranos cada cacicato mantiene dos o tres médicos, o entre médicos y médicas. Una costumbre muy singular reina entre los puelches, y es que los médicos varones andan vestidos de mujer, y en todo hacen, los ministerios de las mujeres, cocinan, traen agua, etc. Lo más reparable es que jamás se acompañan con los hombres, sino con las mujeres". Sánchez Labrador, José: El Paraguay Catholico, citado en Furlong, Guillermo: Entre los pampas..., pág. 56.

32 Garavaglia, Juan Carlos: "Las misiones jesuíticas: utopía y realidad" en Economía, sociedad y regiones, Buenos Aires, 1987. 
mate. ${ }^{33}$ Para nuestro caso, existen indicios de que la implantación de un esquema similar estaba en las mentes de los padres encargados del establecimiento de las misiones del sur del Salado. Al menos eso parece deducirse de la información recogida en la mayoría de los documentos consultados. Sin embargo, si realmente existía, tal objetivo jamás llegó a conseguirse en la práctica. Al contrario de aquel sistema mixto, las fundaciones pampeanas presentan al investigador un modelo de economía escindida, o mejor dos modelos paralelos pero no complementarios de producción.

En un principio, siguiendo las directrices de ese programa de occidentalización que esbozamos más arriba, los padres trataron de iniciar a los neófitos en la práctica de la agricultura. No es casualidad que una de las primeras medidas tomadas al poco de la fundación del poblado de Nuestra Señora de la Concepción, consistiese en el deslinde de terrenos para la agricultura. No parece, con todo, que tratase de implementarse un sistema destinado a la producción y comercialización de excedentes agrícolas, probablemente por la inexistencia de las condiciones necesarias para ello, tanto en el ámbito geológico como sobre todo social. Más bien parece que las esperanzas de autofinanciación se depositaron, por aquel entonces, en la cría y comercialización de ganados. Las referencias a la existencia de grandes estancias son frecuentes, así como las relativas a la existencia de un cierto comercio de ganados, tanto entre las diversas misiones como con la ciudad de Buenos Aires e incluso con los grupos indígenas cercanos ${ }^{34}$. Sin embargo, ni en este caso de las estancias, ni en ningún otro, pudieron los padres aprovechar la mano de obra indígena. Pasadas las euforias iniciales, en todo momento éstos mostraron de manera evidente su negativa a participar en las labores comunales, ya fuese en la construcción del propio emplazamiento, ya en el trabajo de campos o ganados. No les quedó a los padres, por lo tanto, otro remedio que recurrir al conchavo de indígenas de origen guaraní, tapes casi siempre, e incluso mestizos y blancos para la realización de estas labores. La presencia de estos individuos, opuesta al ideal de separación tan propio de la ideología jesuita, es algo en lo que parecen coincidir todos los testigos, tanto aquellos contrarios a la aventura jesuita como los propios padres. Más aun, son notables las referencias existentes a la constante exigencia por parte de los neófitos de pagos y mesnadas para la realización de cualquier tarea. Parece, pues,

33 Garavaglia, Juan Carlos: "Las misiones jesuíticas: utopía y realidad" en Economía, sociedad y regiones, Buenos Aires, 1987.

34 Sobre la estancia de la Concepción, referencias en Furlong, Guillermo: Entre los pampas..., págs. 110,112 y 205 . 
que esto demostraría la inexistencia absoluta de cualquier tipo de vínculo emocional entre el indígena y la misión, la inexistencia de nuevas solidaridades grupales, más allá de aquellas tribales ya pre-existentes. En este sentido, las referencias provienen de las más diversas fuentes:

[Declara el soldado dragón Juan Galeano] que son muy interesados que no moverán una paja sin que les paguen, y que esto lo experimentan los padres pues los conchaban para que hagan cualquier cosa. ${ }^{35}$

porque la naturaleza de estos indios es tan interesada que se ha de juntar la predicción con la dádiva de aquellas cosas que apetecen, y se les ha de estar manteniendo del todo, sin que por sí apliquen a hacer siembras. ${ }^{36}$

sobre todo embaraza los progresos de la reducción el genio interesado de esta gente, no hay forma de reducirlos a matar las vacas que graciosamente les dan los padres y las han de comer estos mismos indios y sus hijos, y es necesario que el misionero pague gente que las mate para que las puedan comer. ${ }^{37}$

A los últimos años, cuando se les caía el techo de la casa, le componían, pero pagándoles el misionero el trabajo y manteniéndoles de yerba del Paraguay y tabaco; de otro modo ni trabajaban par sí mismos, ni para bien de su pueblo. Sucedió algunas veces que los misioneros cuidaban de y tal indio enfermo, hasta guisarle la comida, llevándosela a su casa; convalecía este indio, y le pedía el misionero que le ayudase a hacer alguna cosa de poco afán, como mudar un saco lleno de grano a otro lugar, y el indio ingrato, respondía que le ayudaría, si le daba la paga. ${ }^{38}$

Si les queremos comprar algún caballo o algún poncho para el uso y paga de nuestros peones son tan caros, tan rateros, tan regateadores y tal la vileza de su trato, que a más le traen siempre lo peor, cuesta una importante molestia el ajustar el trato, porque es menester sacarle toda la tienda de vainilla, cascabeles o cuentas de vidrio para escoger, y uno a uno los van tentando, registrando, sonando, desechando a éste por mal color, al otro por mal sonido o mal soldado, la otra por delgada. ${ }^{39}$

En estas condiciones, los modelos económicos indígenas pudieron conservarse sin mayores problemas. Las referencias a expediciones de caza realizadas desde la misión son bien elocuentes al respecto. Se trataba de excursiones de una o dos semanas de duración, llevadas a cabo por

35 Copia de la Información...

35 Carta del obispo de Buenos Aires, don fray José de Peralta, a SM. Buenos Aires. Agosto 24, de 1745. AGI (Sevilla), Charcas, 384.

37 Carta del Padre Provincial de la Compañía de Jesús del Paraguay, Bernardo Nusdorffer, a SM. Agosto 30, de 1745. AGI (Sevilla), Charcas 384.

38 Sánchez Labrador, José: El Paraguay Catholico, citado en Furlong, Guillermo: Entre los pampas..., pág. 106 .

39 Cardiel, José: Diario del viaje..., citado en Furlong, Guillermo: Entre los pampas..., pág. 142. Estas dos últimas citas deben verse con prudencia, toda vez porque las obras de los padres Cardiel y Sánchez Labrador parecen escritas para ilustrar sus teorías sobre lo perverso del contacto entre españoles e indios, tal que los serranos (cercanos a Buenos Aires y con lazos comerciales) serían perversos, los patagones (no contactados) apacibles y receptivos. 
cuadrillas de indios, en ocasiones bastante numerosas, al mando de uno $\mathrm{u}$ otro de sus caciques. Por lo general se realizaban con permiso de los padres, aun cuando la realidad demostrase que esta autorización nunca fue imprescindible:

[Declara el cabo de escuadra Joachim Marin] suelen ir al campo y para esto le dicen al padre me voy a correr yeguas déme VP yerba y tabaco y con efecto se van y se andan cuatro o más días. ${ }^{40}$

[Declara el cabo de escuadra Ramón de Aparicio, sobre la última vez que volvía de Buenos Aires acompañado de algunos indios, autorizados por el padre] en el paso del Saladillo lo alcanzó otro indio llamado don Agustín el ronquillo, a quien el padre no le había querido dar licencia, y como el que declara lo supiese le hizo cargo, diciéndole hombre como te venís cuando el padre no quería y le respondió me voy nomás aquí a las estancias, y se vino hasta el pueblo. ${ }^{41}$

Desde un principio, la misión se convirtió en punto de referencia privilegiado para el comercio indígena, lugar de encuentro e intercambio, en el cual se realizaban numerosas transacciones entre los indígenas pampeanos y aquellos otros llegados de la cordillera. Durante la década de 1740 se produjo la consolidación definitiva del papel de los indígenas pampeanos como intermediarios en el comercio de productos entre el mundo hispanocriollo y el de los pueblos cordilleranos, sobre todo en lo relativo al comercio de ponchos. Para estos años, el poncho parece ser el producto indígena de mayor demanda en Buenos Aires, un producto especialmente valioso tanto por el tiempo que llevaba su elaboración, ${ }^{42}$ como por el elevado precio que podía alcanzar en la ciudad porteña, con frecuencia superior a los veinte pesos. ${ }^{43}$ Gracias a la Copia de la Información..., sabemos que estos ponchos no eran fabricados por los propios pampas, sino que aquellos los obtenían mediante intercambio con los aucas, a cambio de los productos provenientes del Buenos Aires, yerba, tabaco, reses y quizás también

40 Copia de la Información...

41 Ibídem. En el citado legajo del AGI, existen dos copias de esta información, únicamente una de las cuales contiene esta última declaración.

42 Declaraba al respecto nuestro conocido Joachim Marín: "aunque en dicho pueblo hay una india que los hace éstos son balandranes, y se tarda en hacer uno tres o cuatro meses". Copia de la información...

43 Declaraba Antonio Cabral: "y éstos el que menos vale 24 pesos". Copia de la Información... Por otra parte, una idea subjetiva del valor de estos ponchos nos la dan aquellos indios puelches, que tras la captura de varios congéneres en Buenos Aires, pedían a los padres: "Piden, pues, los caciques primero que se les pague a los que han estado presos, o se los vuelva, si no los caballos, a lo menos los ponchos y ropa". Sánchez Labrador, José: El Paraguay Catholico, citado en Furlong, Guillermo: Entre los pampas..., pág. 177. 
armas. ${ }^{44}$ Las referencias al comercio de sables son confusas, aunque parece difícil negar su existencia a la vista de testimonios como los siguientes:

[Declara, una vez más, el cabo de escuadra Ramón Aparicio] y es cierto que los indios de dicho pueblo traen a vender a esta ciudad ponchos de los que compran a los de tierra adentro y que en esta ciudad compran sables y los llevan y se los venden a los indios de tierra adentro por ponchos [...]

[De nuevo Joachim Marin] ha visto en esta ciudad que los dichos indios pampas han comprado sables $[\ldots]$

[Ahora Antonio Cabral, capitán de infantería de milicias] que el que compran y han comprado armas de sables y otras en esta ciudad no hay duda y el que declara lo experimentó en una ocasión que les fue escoltando hasta sacarlos fuera de la jurisdicción, que había indios que llevaban cuatro sables [...]

[Bentura Chavarría, también capitán de infantería de milicias] sí se sabe hayan comprado dichos indios en esta ciudad le consta al que declara que estando de guardia en lo de Jiles en el pago de la Magdalena al cacique Maricá, que había venido mezclado con dichos indios pampas le quitó dos sables que llevaba comprados y que en virtud de ir acompañados de dichos indios de la reducción que había venido con pase del padre Matías Strovel cura de dicho pueblo, y éstos haberle dicho con licencia los habían comprado, se los entregó y permitió que pasasen. ${ }^{45}$

Incluso, en algunas de las crónicas de los padres, aparece el reconocimiento implícito de tal comercio:

Aprestáronse los neófitos, y catecúmenos para la defensa, armáronse de sus coletos, lanzas, sables y bolas y bolas. ${ }^{46}$

Como fuera, con el creciente volumen alcanzado por estos intercambios, comenzaron a producirse intentos de control por parte de las autoridades coloniales, centrados tanto en la restricción de los productos susceptibles de ser comercializados, como en la mediatización del propio intercambio, a través de la implementación de una serie de medidas tales como el establecimiento de puntos fijos de intercambio. Se trata de las

44 Preguntados al respecto, todos los testigos incluidos en la Copia de la Información..., fueron unánimes al respecto: $1^{\circ}{ }^{\circ}$ ) en la Concepción únicamente dos o tres indias fabricaban ponchos $-\mathrm{y}$ éstas casi siempre son citadas como de origen foráneo-; 2..$^{\circ}$ los indios pampas obtenían estos ponchos a través del intercambio con otros grupos nativos del interior. En este sentido, se incluyen afirmaciones tan expresivas cómo la siguiente, del soldado dragón Juan Galeano: “y el modo era que los indios de tierra adentro venían y por inmediato al dicho pueblo paraban en las islas que por allí hay y allí iban los de la reducción a tratar y contratar y les compraban ponchos, y los indios de tierra adentro también venían al dicho pueblo y entraban a él al mismo efecto".

45 Los cuatro testimonios en la tan utilizada: Copia de la Información...

46 Sánchez Labrador, José: El Paraguay Catholico, citado en Furlong, Guillermo: Entre los pampas..., pág. 187 . El resaltado es nuestro. 
famosas ferias de la frontera, como aquélla que señalaban las paces concertadas en 1742 con el cacique Bravo:

2. El Cacique Bravo, y los demás caciques Amigos pondrán sus Tolderías en el Tandil, y Cayrú, y cuando llegase el tiempo de la feria de los Ponchos dará aviso a los Padres Misioneros de la reducción de los Indios Pampas para que se dé esta noticia al Señor Gobernador [...]

4. No obstante que la feria de los Ponchos siempre se ha de hacer en el Tandil, y Cayrú los Indios Amigos podrán bajar, y visitar a los Indios de la reducción de los Pampas cuando quisieren con tal de que no hagan molestia ni a los Padres Misioneros ni a los Indios de la reducción. ${ }^{47}$

Precisamente el acontecer de una de estas ferias, narra la información levantada por el cabildo de Buenos Aires con motivo de las correrías atribuidas a Calelián en el año 1744. Gracias a los testimonios allí recogidos, podemos ver cómo en muchas ocasiones su realización era casi espontánea, correspondiendo a las autoridades el papel de tratar de regularlas, una vez que ya se habían puesto en marcha. Generalmente, estas reuniones eran vigiladas por algunos soldados, encargados tanto de guardar el orden, como de garantizar el cumplimiento de los bandos existentes referidos a la prohibición de comerciar con aguardiente, armas y ocasionalmente también reses ${ }^{48}$ Pese a ello, es evidente que estas restricciones no siempre se cumplían, tanto debido a la propia avaricia de algunos comerciantes, como por consideraciones políticas. En este sentido, el testimonio presentado por el Maestre de Campo, Juan de San Martín, solicitando se revocase la pena de excomunión establecida para quienes violasen estas normas, incluye frases tan significativas como las siguientes:

se sirva exhortar al Venerable Deán y Cabildo Eclesiástico en sede vacante que en consecución de lo expuesto se sirva alzar dicha excomunión en cuanto a la bebida, por ser práctica corriente en el Reino de Chile [...] permitir se les venda dichas bebidas, por conseguir la amistad y sosiego [...] por el justo recelo que esta prohibición sea causa de que se quebrante la paz que con los indios se tiene, la que sirve de sosiego a todo el vecindario. ${ }^{49}$

Más aun, con motivo de la celebración de aquella feria en el año 1744, parece que el gobernador había prohibido la venta de reses a los indios.

47 Capitulaciones de las paces..., págs. 420-421.

48 Bando del gobernador de Buenos Aires, Don Domingo Ortiz de Rozas, con prohibición de vender vino y armas a los indios que llegan a la ciudad para vender ponchos. Buenos Aires, julio 10, de 1744. RAH-CML (Madrid), vol. $2^{\circ}$, pág. 27. Sólo uno entre tantos ejemplos posibles.

49 Actas del Cabildo de Buenos Aires (ACBA, julio 15, de 1747), serie 2 $2^{\mathrm{a}}$, vol. $9^{\circ}$, págs. 262-264. 
Prohibición que sólo se quebrantó en el caso del renombrado Calelián, autorizado por el entonces maestre de campo, Cristóbal Cabral, a llevar algunas de ellas, ya que tales parecían ser, en aquella ocasión objetivo prioritario del interés indígena, probablemente debido a la sequía que ese año azotaba las campañas porteñas. Las prohibiciones, por lo tanto, podían ser quebrantadas dependiendo de la conveniencia política del momento. Con menos éxito, si cabe, se trató desde Buenos Aires de limitar el número de comerciantes indígenas autorizados a bajar a la ciudad capital. Y esto tanto por el peligro directo que estos podían representar para sus habitantes, como debido al temor existente a que actuasen como espías. Una ejemplo, en este sentido, procede de 1754, cuando con motivo de la cercanía de una partida de indios del propio Bravo se estableció por decisión del propio Cabildo:

pacte dicho Maestre de Campo, el que se permitirá que vengan a beneficiar sus efectos cuatro indios, con tal de que sean siempre los mismos los que repitan los viajes y que para su seguridad se les dé competente escolta desde aquella guardia. ${ }^{50}$

De una u otra manera las restricciones fueron siempre soslayadas por aquellos interesados, pues el volumen y la importancia social del comercio con el indígena no decayeron durante todo el periodo..$^{51}$ Un ejemplo claro al respecto lo representa el caso del aguardiente. Es conocido cómo este producto fue siempre uno de los de mayor demanda entre los indígenas, tanto pampeanos como de casi cualquier otra región de las Américas. ${ }^{52}$ En

50 ACBA, serie $3^{\mathrm{a}}$, vol. $1^{\circ}$, págs. 436-437.

51 Mucho más tarde, en 1760, el gobernador de Buenos Aires aun recordaba al comandante de la Matanza, con motivo de la llegada de un grupo de indios serranos, las disposiciones vigentes y reprochaba su no-cumplimiento: "he visto lo que VM me noticia [...] a los indios serranos que en cantidad crecida quieren bajar a esta ciudad con carga de ponchos con el fin de venderlos en cuya inteligencia debo prevenir a VM que no conviene que vengan todo género de naciones porque con estos pretextos se hacen prácticos de todos los pasos lo que puede ser muy perjudicial, para esta campaña y aun al presente se está experimentando, que por todas partes se van introduciendo indios, y animándose cada día más y más, por semejantes tolerancias, y permisos, de manera que antes no se permitía bajar aquí más que aquellos de quienes se tenía satisfacción, y a quienes después de largas experiencias se les había concedido la Paz, y de estos eran muy pocos los que venían con grande precaución presentándose en la guardia del Zanjón donde dejaban las armas si las traían”. Comunicación del gobernador de Buenos Aires al Comandante de la Matanza José A. López. Buenos Aires. Octubre 29, de 1760. AGN, Comandancia de Fronteras, IX, 1-4-5 citado en Mandrini, Raúl: "Las transformaciones de la economía indígena bonaerense (ca. 1600-1820)", en Mandrini, Raúl y Reguera, Andrea (comps.), Huellas en la tierra: indios, agricultores y hacendados en la pampa bonaerense, Tandil, 1993, pág. 125.

52 Igualmente en años algo posteriores, Louis de Bougainville, viajero francés, señalaba los extremos a que podía conducir el consumo de aguardiente, entre los indígenas conchavados en las pampas de Buenos Aires: "A veces vienen los indios con sus mujeres a comprar aguardiente a los españoles; no cesan de beberlo hasta que están completamente embriagados y ya no pueden ingerir. Para 
el caso de la Pampa encontramos auténticos profesionales de la aventura, comerciantes capaces de adentrarse más allá de la frontera, hasta las cercanías de las misiones, para permanecer allí por semanas e incluso meses, en campamentos provisionales, a los cuales atraían multitud de neófitos, con el consiguiente disgusto de los padres. El siguiente párrafo, copiado de la crónica del padre Sánchez Labrador, que citamos por extenso dado lo significativo de lo que en él se narra, refleja esta situación:

para que se vea hasta dónde llegó la perfidia de los desventurados pulperos y los atrasos que causaban a la predicación del Evangelio, me contentaré con referir algo de lo mucho que hicieron. El año de 1748 fueron unos pulperos a poner su taberna a distancia de tres leguas de la reducción del Pilar. Lo mismo hicieron el año de 1750. La primera vez lograron de lleno su intento, enajenando los indios y atrayéndolos; no así en la segunda, porque aunque iban a comprarles aguardiente algunos indios, los más se quedaban con los misioneros, no queriendo desperdiciar sus cosillas. Viendo un pulpero que no le salía bien su intento, inventó una traza diabólica. Fingió que era enviado de Buenos Aires a la Reducción del Pilar para que los misioneros hicieran diligencia de un cautivo español que estaba tierra adentro. En este tiempo trató con dos caciques, los exhortó a que dejasen la reducción y se fuesen con sus gentes al río Salado que dista 30 ó 40 leguas de Buenos Aires. En efecto los dos caciques persuadidos de la astucia del pulpero, levantaron sus toldos y caminaron al lugar dicho, donde los halló el padre Agustín Vilert en una solemne borrachera. Siete meses se detuvieron los indios con el pulpero, que habiéndolos sacado cuanto tenían y dejándolos pereciendo, se fue a Buenos Aires a gozar del fruto adquirido con sus fraudes y maldades..$^{53}$

La historia es bien jugosa, al tiempo que presenta interesantes detalles sobre la magnitud alcanzada por el comercio semi-legal de aguardiente. Fijémonos, por ejemplo, cómo el mencionado pulpero debió recorrer casi mil kilómetros, en su mayoría por territorio enemigo, antes de alcanzar su destino. Incluso, a partir de estos años comienzan a encontrase en la documentación referencias a pulperos pampas, lo que, claramente, nos está hablando de un mundo cada vez más complejo, cuyos detalles y alcance no han sido estudiados por el momento:

Con el padre Tomás Falkner llegó acá Juancho Manchado; vendió bastante aguardiente [...] es ésta la sexta vez desde que estoy aquí, que han llegado estos borrachos y pulperos pampas acá con aguardiente. He oído también de diferentes, que todo el

obtener sus licores fuertes, venden sus armas, pieles y caballos. Una vez que han vendido todo lo que poseen, capturan algunos caballos de las habitaciones vecinas y huyen de regreso a sus tierras". Citado en León Solís, Leonardo, Maloqueros y conchavadores en..., pág. 117.

53 Sánchez Labrador, José: El Paraguay Catholico, citado en Furlong, Guillermo: Entre los pampas..., pág. $150-151$. 
tiempo que ha durado el trato de ponchos, Juancho patricio trajo e hizo traer a escondidas aguardiente de la ciudad vendiéndolo por ponchos. VR diga a estos infames pulperos pampas, ya que no nos ayudan en nada en la conversión de éstos sus paisanos y parientes, a lo menos no nos embaracen. ¿Qué bendición de Dios pueden esperar estos malos ministros de Satanás? $?^{54}$

En conclusión, pese a las aspiraciones de los padres, la separación entre ambos mundos nunca pasó de ser un ideal. La existencia de una serie de circuitos comerciales en proceso de consolidación imposibilitó su implementación en el espacio pampeano. Tanto indígenas como criollos, comenzaban a ver en la extensión de estos circuitos, en el creciente volumen de intercambio que generaban, una posibilidad de desarrollo sumamente atractiva. Dentro del juego de poder interno de ambos mundos, la existencia de estas redes contribuía al proceso de consolidación de las incipientes elites que en ambos mundos estaban surgiendo por aquellos años. De este modo, las misiones representaban algo así como un contrasentido histórico, una alternativa difícil de asumir, cuyo interés limitado se centraba en su utilidad a corto plazo, por una parte como espacio privilegiado de intercambio, por otra como centro redistribuidor de bienes. En este sentido, son numerosas las referencias existentes al respecto. Ya hemos visto cómo los padres necesitaban de la constante entrega de regalos para asegurar la atención de los neófitos. Pero más allá de eso, también los grandes caciques recibían su tributo, tal como refleja la siguiente cita:

El padre Tomás [Falkner] ya tarda; el cacique Bravo Don Nicolás estuvo ayer conmigo; está esperando las 50 vaquitas que tiene prometidas. ${ }^{55}$

Sobre este mismo asunto, el interés de determinados sectores dentro de la sociedad pampeana por consilidar relaciones con las sociedad hispano-criolla, gravita, la problemática en torno al idioma de predicación que debía ser empleado en las misiones. Es un punto interesante. Se ha señalado cómo la utilización de las lenguas indígenas por parte de los jesuitas respondía a esa misma lógica de aislamiento que hemos comentado más arriba que era uno de los pilares del proyecto jesuita. Así opinaban, al menos,

54 Carta del padre Matías Strobel al padre Jerónimo Rejón. Nuestra Señora del Pilar. Noviembre 20, de 1748. AGN (Buenos Aires), Compañía de Jesús, 1748. Ambos Juanchos, Patricio y Manchado, aparecen nombrados con asiduidad en la Copia de la Información... en distintos roles, siempre relacionados con el comercio.

55 Carta del padre Matías Strobel al padre Gerónimo Rexón. Nuestra Señora del Pilar. Junio 23, de 1748. AGN (Buenos Aires). Compañía de Jesús, 1748, citado Furlong, Guillermo: Entre los pampas..., pág. 153 . 
Helene Clastres y Bareiro Seguier en su trabajo sobre las misiones guaraníes. ${ }^{56}$ Del mismo modo, los padres pampeanos trataron, desde un primer momento, de aprender las lenguas nativas, pese a la dificultad que la diversidad de estas representaba. En su libro sobre el tema, el padre Furlong nos habla incluso de un presunto catecismo pampa, que estaría perdido, al parecer escrito por Matías Strobel. ${ }^{57}$ Sin embargo, desde muy temprano, la pretensión de los padres de desarrollar la tarea evangelizadora utilizando las lenguas nativas, enfrentó con la oposición de los propios interesados, los pueblos indígenas de la pampa, renuentes a recibir la prédica en sus propias lenguas, tanto en el caso de los pampas de la Concepción como en el de los serranos del Pilar:

[En la Concepción] advirtieron después los misioneros, que eran muchos más los que entendían lo que se les decía; y que todos no penetraban el sentido español, por no ser su idioma. Con esta experiencia se aplicaron los misioneros a aprender su propio lengua, lo que les costó notable trabajo. Ningún indio quería servirles de maestro [...] el padre les hacía en su lengua las preguntas de la doctrina cristiana: pero los indios no le querían responder. De modo que en esta lengua española no entendían la doctrina; y puesta en su idioma ni respondían ni querían aprenderla, con que tenían en tortura los corazones de los misioneros. Ayudó también mucho a la obstinación de los indios, la diversidad de lenguas, que había entre ellos..$^{58}$

[En el Pilar] no se puede omitir la guerra que con un raro estratagema hizo el demonio a los misioneros en orden al rezo y doctrina cristiana, para que los indios, hombres y mujeres, se hiciesen cargo de verdades tan importantes, se les hablaba en su propio idioma. Amotináronse en varios idiomas, diciendo a los padres que si querían enseñarles, había de ser en la lengua española, y no en la suya natural. ${ }^{59}$

Para explicar esta negativa debemos tanto en términos de representación como de utilidad práctica. Es evidente que el castellano era percibido entre los propios indígenas como la lengua propia de la religión cristiana, aquélla en que debía ser predicada. Si se trataba de asimilarse al modelo español, lengua y religión debían ir juntas, tal como comprobaron aquellos cuatro neófitos al bajar a Buenos Aires:

Concurrió mucho a esta contradicción de los indios el caso siguiente: fueron algunos neófitos a Buenos Aires, y cierto español les preguntó algo de la doctrina; respondieron por medio del intérprete, que la sabían solamente en su lengua, y diciendo

56 Bareiro Saguier, Rubén y Clastres, Helene: "Aculturación y mestizaje...

57 Furlong, Guillermo: Entre los pampas..., pág. 96.

58 Sánchez Labrador, José: El Paraguay Catholico, citado en Furlong, Guillermo: Entre los pampas..., pág. 96.

59 Ibídem, pág. 160. 
y haciendo, se persignó un indio. El buen español les afeó mucho el que rezaran la doctrina cristiana en su lengua, que no era lengua de cristianos. Como los indios no tenían luz para poner en estrechuras con retorsiones al castellano, se avergonzaron y dieron queja a los misioneros. ${ }^{60}$

Paralelamente la lengua española era, por aquellos años, la propia del intercambio en la región sur de Buenos Aires. Su aprendizaje y conocimiento facilitaba las relaciones interculturales, al tiempo que aumentaba las posibilidades de éxito en un mundo en transformación y, como tal, pleno en oportunidades nuevas. ${ }^{61}$ Una vez más, las fuentes son explícitas al respecto. Mientras un creciente número de indígenas, tanto pampeanos, como serranos, aucas o patagones, tanto reducidos como libres, dominaba la lengua española, eran muy pocos los hispano-criollos que hablaban algún idioma nativo. ${ }^{62}$ Es significativo el ejemplo del soldado Blas de Espinosa, quien tras siete años de permanecer de guardia en la reducción de Nuestra Señora de la Concepción, declaraba: "pues aunque tenía muchos amigos cuando estaba en la reducción de los indios de ella y los oía estar hablando en su lengua no les entendía lo que decían". ${ }^{63}$

El castellano era, por lo tanto la lengua del contacto interpersonal. Su aprendizaje suponía una mayor facilidad para el comercio, para el intercambio. Como estrategia de éxito aparece, incluso, un cierto nivel de aculturación, de pretendida asimilación, como la que se observa en los siguientes ejemplos. En ello el uso de productos provenientes del mundo hispano-criollo aparece explícitamente documentado, y no sólo en manos de caciques u hombres poderosos, ni necesariamente en las cercanías de las reducciones, tal como evidencia el segundo caso, documentado para la bahía de San Julián, en fecha muy anterior al establecimiento del fuerte del Carmen:

60 Ibídem, pág. 161.

61 Tanto en la Información..., como en la Copia de la Información..., y en la demás documentación de época abundan las referencias al uso del castellano como lengua comercial, con tal profusión hasta el punto de hacer inútil incluir citas exactas al respecto.

62 Aunque también entre los hombres de la frontera había quien se expresaba con fluidez en alguna de las lenguas nativas. Como aquel capitán Antonio Gutiérrez, cuya viuda cuenta cómo, frente a una partida de indios infieles, que había llegado hasta su hacienda con el explícito deseo de matarle: "le nombraron por su nombre convidándole a pelea; pero como su valor no reparase en el número de indios que se habían juntado sin poderse contener por más que le aconsejaban los compañeros reparándose éstos se desfiló animándoles le siguiesen [...] y después de haber tenido [los indios] con el expresado mi difunto debate en la lengua que también él conocía se empezó la pelea". Memorial de doña María Rosa de Rocha, viuda del Capitán Antonio Gutiérrez, a Su Excelencia el gobernador de Buenos Aires. Ciudad. 1753. AGI (Sevilla), Buenos Aires, 159.

63 Copia de la información... 
[Declara sobre su cautiverio Rafael de Zoto] un indio de los veinte que estaban en su compañía pastoreando los animales de su amo, ladino en castellano, muchacho criado que fue del padre Mathias le ha dicho al que declara que muchas veces ha venido al pueblo y ha comprado yerba y aguardiente y se ha vuelto a ir y esto no pone en duda el que declara haya sido así pues cualquiera que lo vea y lo hable como no lo conozca no dirá que es indio pampa sino otro cualquiera de los amigos pues el traje es como de cristiano con calzones chupa y camisa y lo demás que se usa [...] y añade que cuando lo llevaron cautivo los alcanzó un indio ladino llamado Lorenzo por allá enfrente del Volcán el cual no sabe de dónde salió sólo sí le oyó decir era de la reducción del Volcán y que había venido a la ciudad el cual iba vestido de calzones chupa y lo demás, y siempre anda vestido de la misma forma aun allá tierra adentro. ${ }^{64}$ A los pocos días después, en las expresadas lagunas hallaron más de 1.400 indios con sus hijos y les recibieron con la misma paz y cariño que antecedentemente, y dicen son de grande estatura, tanto hombres como mujeres, y que entre ellos habría como 600 hombres de pelear, y tienen tres caciques, uno de ellos españoleado. ${ }^{65}$

Pero los avatares de la comunicación no concluían aquí. No sólo se trataba de la lengua, de aprender el castellano. Pablo Morandé ha señalado la dificultad de compatibilizar una religión basada en la palabra, como ha sido siempre la cristiana, con aquéllas otras esencialmente culturales, propias de los indígenas sudamericanos. ${ }^{66} \mathrm{La}$ dificultad de transmitir el mensaje, de hacerlo compatible con las representaciones religiosas indígena aparece explícitamente reflejado en multitud de casos cotidianos. El choque constante con las creencias ancestrales de los nativos, con sus ritos y especialmente con sus tabúes, son experiencias reiteradas. ${ }^{67}$

Otro motivo de ejercitar la paciencia en orden al rezo tuvieron los misioneros del Volcán. Fue el caso que los indios australes tienen una ley bárbara de que los que tiene su padre ya difunto, y lo mismo los que tiene muerto algún hijo, no han de nombrar estas palabras: Padre, Hijo. Como en el rezo ocurren varias veces esas palabras no había forma ni fuerza para hacer que las profirieran [...] eran por demás sermones y explicaciones para convencerlos [...] en cierta ocasión un indio patagón que enseñaba su idioma al padre Lorenzo Balda, en presencia de éste, y de otros dos misione-

\section{Ibídem}

65 Barne, Jaime: "Viaje que hizo el San Martín desde Buenos Aires al puerto de San Julián, el año de 1752; y del de un indio paraguayo, que desde dicho puerto vino por tierra hasta Buenos Aires" en Colección de viajes y expediciones a los campos de Buenos Aires y a las costas de la Patagonia, a su vez en De Angelis, Pedro: Colección de obras y documentos relativos a la historia antigua y moderna de las provincias del Río de la Plata. Buenos Aires, 1836-1837, Tomo III, pág. 90.

66 Morande, Pedro: Ritual y palabra, Lima, 1980.

67 Sobre la debatida cuestión del discurso y su difícil transmisión entre culturas orales y escritas, pueden consultarse dos clásicos cómo son: a) Dijk, Teun van: Estructuras y funciones del discurso, Ciudad de Méjico, 1988, y b) Ong, Walter: Oralidad y escritura: Tecnologías de la palabra, Ciudad de Méjico, 1987. 
1753)

ros manifestó la repugnancia que tenía en proferir las palabras dichas. Preguntáronle los misioneros en lengua puelche como se decía en lengua patagona lo que querían saber $[\ldots]$ al fin pudieron alcanzar que hablara, pero lo hizo en voz tan baja y tan entredientes, que no le percibieron nada. Obligáronle con dádivas a que hablara de manera, que percibieran estos vocablos: Ma Glater, Ma Meme. Profiriólos repetidas veces el padre Balda, diciendo al indio que estos nombres no encerraban cosa mala. Entonces el indio, siendo así que era de muy bella índole, montando en cólera, se levantó porfiando en dejar a los padres y diciendo: Calla padre, que no sabes que injuria cometes. Nosotros tenemos ley inviolable de quitar la vida a cualquiera, que en nuestra presencia profiera estas palabras. ${ }^{68}$

[De nuevo el cautivo Rafael de Zoto] nunca serán buenos cristianos y esto se confirma con lo que les oyó decir el declarante a las tres indias muchachas allá en la sierra el Guaminí las cuales una se llamaba Polonia, otra Luisa, y la otra Brígida de que el propio padre Mathias en la reducción del Bolcán les había lavado la cabeza y que para esto les había dado pasas y bizcocho, dejándose entender que habiéndoles instruido en la doctrina y demás necesario para ser cristiano, les bautizó haciéndoles aquellos halagos que ellos entendían por paga. ${ }^{69}$

\section{La violencia cotidiana y el quiebre de la misión}

Alejados de Buenos Aires, incomprendidos por quienes habían de ser sus neófitos e incapaces de imponer su autoridad entre ellos, los padres hubieron de recurrir desde temprana fecha a la ayuda del gobernador, aceptar en definitiva la instalación permanente de retenes de soldados dragones en el interior de cada una de las misiones. Quizás por vez primera en su historia, las sociedades indígenas pampeanas, los grupos reducidos en este caso, se enfrentaban a la existencia de una fuerza coactiva, interesada en $-\mathrm{y}$ con capacidad para - regular la cotidianeidad de sus vidas. Padres junto a soldados representaban el embrión de una nueva organización social, que podríamos definir como paraestatal, radicalmente diferente de las organizaciones sociales mucho más flexibles en que estos indígenas habían vivido hasta ese entonces. Más allá de las protestas de amor y cariño con que los padres jesuitas rodeaban su propia literatura referente a su accionar en las pampas, contamos con los suficientes testimonios para evidenciar la real utilización de la fuerza física, durante el proceso de evangelización y occidentalización:

68 Sánchez Labrador, José: El Paraguay Catholico, citado en Furlong, Guillermo: Entre los pampas..., págs. 161-162.

69 Copia de la Información... 
[Declara el soldado dragón Juan Galeano] siempre venía el padre al cuartel y le pedía al cabo que despachase gente a los ranchos de los indios a que los trajesen a la iglesia [...] que sólo los muchachos suelen ir a la doctrina y esto es porque los padres les dan sus pasitas $[\ldots]$

[Declara Gregorio Velasquez, también soldado dragón] en el tiempo que él estuvo de guardia un indio se fue a la sierra sin licencia del padre, y luego que éste vino el padre lo puso en el cepo. ${ }^{70}$

Una violencia, sin embargo que no hay que creer unilateral. Más bien un ambiente general, en buena parte provocado por la distorsión de los modelos tradicionales de asentamiento, por la convivencia cotidiana de diversos grupos en un mismo espacio físico:

Conservan entre sí muchas enemistades, que cuando están bebidos prorrumpen en pendencias y muertes, y a fines del año próximo pasado quedaron por esa causa tres muertos de una parcialidad más casi todos heridos de la otra. ${ }^{71}$

De los ejemplos anteriores, se evidencia cómo la coacción directa terminó por convertirse en un elemento del acontecer diario, incluso en la propia mecánica de la cotidianeidad, transformando las misiones en algo similar a lo que hoy llamaríamos un estado policial. De este modo, si recapacitamos sobre todo lo escrito hasta este punto, resulta claro que la labor de los padres en la pampa representaba un elemento desestabilizador de primer orden para aquellos grupos indígenas inscritos dentro del radio de su campo de influencia. En primer lugar, por cuanto suponía la existencia de una fuente proveedora de bienes - materiales y espirituales - exterior a las estructuras tradicionales de la organización social. Con el tiempo, necesariamente ese elemento de distorsión había de terminar por convertirse en un obstáculo para la consolidación de los estrategias políticas de buena parte de los actores sociales nativos, implicados en las transformaciones que por aquel entonces afectaban a la sociedad indígena en su conjunto. Un elemento fundamental de estas estrategias era la extensión de lo que, utilizando una definición muy laxa, podríamos llamar un sistema de patronazgo y clientela. Con ello, una sociedad aparentemente igualitaria hasta un pasado cercano, comenzaba a reproducir en su interior procesos de jerarquización social. ${ }^{72}$ No debe pen-

70 Copia de la Información... En este sentido, todas las declaraciones son monótonas repeticiones, presentando siempre tal o cual ejemplo concreto.

71 Carta del Padre Provincial de la Compañía de Jesús del Paraguay, Bernardo Nursdoffer, a SM. Buenos Aires. Agosto 30, de 1745. AGI (Sevilla), Charcas 184.

72 Al respecto: Mandrini, Raúl: "El viaje de la fragata San Antonio en 1745-1746. Reflexiones sobre los procesos políticos operados entre los indígenas pampeano-patagónicos”, en Revista Española de Antropología Americana, núm. 30, Madrid, 2000, págs. 235-263 
sarse en una competencia directa entre padres y caciques en lo referente al control de estas incipientes redes. Desconocemos si estuvo en la mente de los jesuitas una posible estrategia de reorientación de fidelidades personales, pero en todo caso, del estudio de la representación que los propios indígenas se hacían de su accionar entre ellos, resulta evidente que ello habría resultado imposible, tal como quedó evidenciado más arriba. ${ }^{73}$ Más bien, el reparto cotidiano de regalos y dádivas por parte de los padres entre los fieles concurrentes al templo, planteaba la existencia de lo que Moses Finley - para un contexto bien distinto- ha llamado nuevas formas de un seguro de subsistencia. ${ }^{74}$ Esto es, dado que la capacidad de influencia del incipiente cacique indígena no podía basarse aun en una inexistente capacidad de coacción física, la clave de su posición radicaba en el mantenimiento de su estatus de proveedor principal de bienes, tanto de primera necesidad en momentos de crisis, como de lujo en las demás situaciones del acontecer cotidiano. La existencia de un mecanismo paralelo de redistribución, estuviese éste orientado o no a la creación de redes de clientelas, necesariamente debilitaba esta posición de privilegio, posibilitando un debilitamiento de fidelidades. Esto ocurría a dos niveles. Primero, como ya ha quedado claro, dentro del propio grupo. Pero también —o sobre todo- afectaba a la articulación de los distintos grupos entre sí, casi anulando los débiles lazos de dependencia que por entonces comenzaban a ligar unos con otros.

Uno de los caciques solicitados a la guerra contra los españoles era Ayalep, de nación picunche, deudo muy cercano del mismo Bravo. Dicho cacique más racional y de mejor corazón que Bravo, atendiendo contra quienes dirigía su pariente las armas, le respondió: que no estaba en ánimo de pelear, ni molestar a los españoles, y mucho menos a los padres misioneros, de los cuales jamás había recibido agravio, pero sí muchos beneficios, siempre que había ido a visitar los pueblos. ${ }^{75}$

Era [el cacique auca Nahualpil] el primero que entraba en la iglesia a la explicación de la doctrina, al Rosario, y al Santo Sacrificio de la misa. En todas estas funciones se hacía distinguir su compostura devota y atenta [...] aunque los puelches, que aun no mostraban tanta, le reprendían, y hacían burla, diciéndole que se hacía español, y tirándole por esto a la cara varios apodos. ${ }^{76}$

73 Al respecto, ya hemos visto como para la consolidación de tal empeño, faltaban en los padres muchos de los componentes básicos de la arquitectura del jefe tribal, especialmente los relacionados con su función de conductores bélicos. El suyo, el de los padres queremos decir, era un rol demasiado ambiguo como para llegar a fructificar, al menos en aquel momento.

74 Finley, Moses I.,: El nacimiento de la política, Barcelona, 1986, págs. 65-70.

75 Sánchez Labrador, José: El Paraguay Catholico, citado en Furlong, Guillermo: Entre los pampas..., págs. $187-188$.

76 Ibídem, pág. 166. En un mundo fragmentado, la cristianización venía pues a representar una nueva línea más de quiebre de solidaridades. 
Pasemos por alto las apreciaciones personales de nuestro cronista. Pero aun de esta manera, aun siendo los principales favorecidos por este reparto, los caciques acabaron por encontrar en los padres una amenaza al proceso de consolidación de su incipiente poder. Para el caso resulta indiferente que este pensamiento se formulase conscientemente o no. Tampoco hemos de pensar en la ausencia de capacidad de análisis política, más allá de consideraciones sobre el lenguaje científico de nuestros términos. Lo importante era la presencia del competidor, una presencia evidente, diaria, capaz de subvertir, por sí misma, las estructuras tradicionales del poder. Una vez más, nos encontramos ante una situación altamente compleja, con fenómenos de incidencia ambigua e incluso ambivalente, como éste del reparto de bienes. Es importante ponderar los momentos concretos, la evolución de las coyunturas sobre la base de acontecimientos y contextos mutables. Las cambiantes evoluciones de las distintas líneas de fuerza que actuaban en el complejo mundo de las interrelaciones entre ambas culturas, indígena e hispano-criolla. Un número importante de actores estaba en el juego, tejiendo complejas alianzas de intereses que podían deshacerse a cada momento, para reconstruirse poco después sobre nuevos términos. En este sentido, son inteligibles los cambios de actitud, a veces tan bruscos como sorprendentes, de unos y otros. Hemos de leerlos como resultantes de micro-procesos de alcance local, a través de los cuales una u otra faceta de estos procesos ambiguos - consolidación de jerarquías, malones, reparto de bienes misionales- quedará provisionalmente resaltada: la excesiva capacidad de un padre concreto, como por ejemplo Falkner, para asegurarse la fidelidad de un grupo importante de indígenas, la necesidad coyuntural del reparto de bienes por parte de los grandes caciques de acuerdo a las crisis periódicas de alimentos y epidemias, la importancia de la presión militar española en un momento concreto... Por ello, como decíamos más arriba, no puede verse la desaparición de las misiones como el resultado del triunfo absoluto de una u otra de estas tendencias, de uno u otro de los distintos grupos de interés, presentes en ambos mundos. Se trataría más bien de la conjunción de una serie de coyunturas concretas, a partir de las cuales, en el despliegue de sus estrategias propias de poder, los intereses de un número suficiente de actores sociales habrían determinado la extinción de estas reducciones. Igualmente, el análisis de su no reconstrucción provendría de unos parámetros similares, de la aparición de nuevas tácticas, a los ojos de los contemporáneos potencialmente más prometedoras a la hora de lograr sus objetivos en la confrontación social en el mundo de la política cotidiana. 